\title{
The Difference between the Therapeutic Effects of Thiamine \& ACEI as Therapeutic Agents for the Control of Blood Glucose and ABP in Type II Diabetic Rats, A Comparative Study
}

\author{
MOHAMED M. KHALIFA, M.D. ${ }^{1}$; AKEF A. KHOWEILED, M.D. ${ }^{1}$; MINA J. AYAD, M.Sc. ${ }^{2}$; \\ HANAN FOUAD, M.D. ${ }^{3}$ and MAHMOUD R. MOHAMED, M.D. ${ }^{4}$ \\ The Department of Medical Physiology, Kasr Al-Ainy Faculty of Medicine, Cairo ${ }^{1}$ and MUST Universities, \\ The Department of Biochemistry, Kasr Al-Ainy Faculty of Medicine, Cairo University ${ }^{3}$ and \\ The Department of Microbiology and Immunology, MUST University ${ }^{4}$, Egypt
}

\begin{abstract}
Background: Thiamine is a vitamin with a widespread physiological functions and therapeutic effects. Its beneficial effects in different diseases conditions is the subject area of multiple recent researches. Especially in chronic diseases as diabetes and hypertension.

Aim of the Study: Test and compare the possible protective effects of angiotensin converting enzyme inhibitor and thiamine in type 2 diabetic rats.

Patients and Methods: A total of 55 male albino rats were used in this study weighing 150-200 grams. The animals were housed in wire mesh cages at room temperature, with normal light dark cycle. They were fed the commercial rat chew diet and had free access to water. These rats were divided into the following groups: Group 1: Control group, Group 2: Type 2 diabetic rats, Group 3: Type 2 diabetic nephropathy rats, Group 4: Lisinopril-treated type 2 diabetic nephropathy rats, Group 5: Thiamine mononitrate-treated type 2 diabetic nephropathy rats. Blood samples were collected for measurement of fasting blood glucose, fasting blood insulin. Homeostasis model assessment of insulin resistance was calculated. Systolic blood pressure and diastolic blood pressure were also measured. Nuclear factor kappa B gene expression was estimated.

Results: Treatment with angiotensin converting enzyme inhibitor reduced fasting blood glucose, fasting blood insulin, nuclear factor kappa B gene expression, systolic blood pressure and diastolic blood pressure. While treatment with thiamine mononitrate reduced fasting blood glucose and systolic blood pressure.

Conclusion: The use of angiotensin converting enzyme inhibitor and thiamine in the treatment of type 2 diabetes significantly improved the ABP and the diabetic condition in type 2 diabetes mellitus. ACE inhibitors also inhibits the inflammatory cascade.
\end{abstract}

Key Words: Diabetes - Hypentension - ACE inhibitors Thiamine-Nuclear factor kappa $B$.

Correspondence to: Dr. Mohamed M. Khalifa, E-Mail:m mmk2050@yahoo.com

\section{Introduction}

DIABETES Mellitus (DM) is one of the most common clinical metabolic disorders and its prevalence is gradually increasing. Its prevalence is growing both in developed and developing countries. Currently more than $5 \%$ of adults have this disease, with its prevalence rising from $1 \%$ in the youth to $13 \%$ in adult older than 60 years [1]

Hyperglycemia, the common feature of all types of diabetes, appears to cause tissue damage by both acute reversible changes in cellular metabolism and cumulative, irreversible changes in macromolecules. The possible biochemical mechanisms are diverse, including the activation of the polyol pathway, and the activation of Protein Kinase C (PKC), formation of glycation end products and increased oxidative stress [2]. Hyperglycemia also leads to increased oxidative stress leading to peroxidation of lipid membranes, proteins and DNA [3]

The formation of Advanced Glycation Endproducts (AGEs) by non-enzymatic binding of glucose to various organic molecules such as proteins, lipids, nucleic acids and other molecules can lead to the alteration of protein structure and function, oxidative stress, and expression of proinflammatory cytokines and growth factors [4]

Oxidative stress and the subsequent generation of Reactive Oxygen Species (ROS) damage deoxy ribonucleic acid (DNA) and protein, or function as signaling amplifiers to activate cellular stress pathways such as Protein Kinase C (PKC), Mi- 
togen-activated Protein Kinase (MAPK), and nuclear factor kappa B (NF- $\kappa \mathrm{B})$ [5].

Activation of the polyol pathway, with aldose reductase converting excess glucose to sorbitol, and subsequent conversion to fructose by sorbitol dehydrogenase contributes to oxidative stress [6]

Glycosylation of tissue proteins contributes to pathological change in the kidney leading to the development of DN and other microvascular complications. In chronic hyperglycemia, some of the excess glucose combines with free amino acids on circulating or tissue proteins. This non-enzymatic process affects the glomerular basement membrane and other matrix components in the glomerulus and initially leads to formation of reversible early glycosylation end products and, later, irreversible advanced glycosylation end products. These advanced products claimed to be involved in the pathogenesis of DN by altering signal transduction via alteration in the level of some soluble signals, such as cytokines, hormones and free radicals [7]

Diabetic nephropathy is becoming the most common cause of renal failure and End-Stage Renal Disease (ESRD) in most countries and carries an increased risk of cardiovascular mortality. It is described as a syndrome characterized by the presence of pathological quantities of urine albumin excretion and diabetic glomerular lesions [8]

ACE inhibitors are a class of drugs thought to make a significant difference for patients with diabetes as a whole. If patients both with and without microalbuminuria are compared together, ACE inhibitors significantly reduce the progression of albumin excretion rate. ACE inhibitors prevent the conversion of angiotensin I to the active compound angiotensin II. They can decrease tissue oxidative stress, and there is an evidence that they lower the formation of AGEs [9]

It is now realized that the ability to block tissue ACE (particularly in the kidney) is more important than the ability to block circulating ACE [10] .

Dysregulation of RAAS plays an essential fundamental role in the pathogenesis of various complications of diabetes mellitus especially the diabetic nephropathy. The pathological hallmarks of DN include expansion of mesangial cells, accumulation of extracellular matrix protein, thickening of glomerular and tubular basement membranes, tubulointerstitial fibrosis, glomerulosclerosis and renal endothelial dysfunction [11]
Hyperglycemia is usually associated with increased production of ANG II in glomerular mesangial cells, which leads to accumulation of ROS exacerbating the oxidative stress occurring in diabetes mellitus. And also leading to gradually subsequent elevation of arterial blood pressure, through the production of aldosterone or by increasing the vasoconstrictor tone [12].

Thiamine, or vitamin B 1, named as the "thiovitamine" is a vitamin of the B complex. It is a water-soluble vitamin. Its phosphate derivatives are involved in many cellular processes. The bestcharacterized form is thiamine diphosphate (ThDP). A recent study revealed allosteric regulation of metabolic enzymes by non-coenzyme forms of thiamine, which may be responsible for the action of thiamine and its derivatives as metabolic regulators [13].

Thiamine acts as a coenzyme for Transketolase (TK) and for the pyruvate dehydrogenase and alpha-ketoglutarate dehydrogenase complexes, enzymes which play a fundamental role in intracellular glucose metabolism. A thiamine/TK activity deficiency has been described in diabetic patients

Thiamine and its derivatives have been demonstrated to prevent the activation of the biochemical pathways (increased flux through the polyol pathway, formation of advanced glycation end-products, activation of protein kinase $\mathrm{C}$, and increased ion flux through the hexosaminebiosynthesis pathway) induced by hyperglycemia in DM and it is suggested that it has a role in the diabetic endothelial vascular diseases (micro and macroangiopathy) [15].

Thiamine reserve was found to be reduced in litters of untreated diabetic rats [15].

Thiamine deficiency appears to impair the normal endocrine function of the pancreas and exacerbate hyperglycemia. Early studies showed that insulin synthesis and secretion were altered in the endocrine pancreatic cells of thiaminedeficient rats [15].

A wide range of proinflammatory molecules and pathways participate in the pathophysiological spectrum of diabetic nephropathy, including proinflammatory cytokines, chemokines and their receptors, adhesion molecules and transcription factors. Kidney cells can synthesize proinflammatory cytokines, and the expression of chemoattractant cytokines and other adhesion molecules is upregulated in kidney cells from patients and animals 
with diabetes. These molecules are key mediators of renal injury and other diabetic complications by virtue of their ability to attract the circulating white blood cells (monocytes, neutrophils and lymphocytes) and facilitate transmigration of these blood cells into renal tissue. These infiltrating cells are a source of cytokines and other mediators that can contribute to the development and progression of renal injury, as well as to amplification and perpetuation of other inflammatory reactions [16]

Recent evidence suggests that if there is insulin resistance, the pancreas is forced to increase its insulin secretion, which stresses the $\beta$ cells, eventually resulting in $\beta$-cell exhaustion. This high blood glucose level together with the high levels of saturated fatty acids create an inflammatory medium, resulting in activation of the innate immune system, resulting in activation of the NF$\kappa \mathrm{B}$, and the release of other inflammatory mediators, including, IL- $1 \beta$ and TNF- $\alpha$, promoting systemic insulin resistance and $\beta$-cell damage as a result of autoimmune insulitis. Insulin resistance further leads to high glucose levels, along with high serum levels of free fatty acids and IL-1, leading to glucotoxicity, lipotoxicity, and IL-1 toxicity, resulting in apoptotic $\beta$-cell death [17].

Angiotensin II has been added to the list of important molecules that activate NF- $\kappa \mathrm{B}$. Angiotensin II activates NF- $\kappa B$ in the kidney via Angiotensin II receptor type 1 (AT 1R) and Angiotensin II receptor type 2 (AT2R), and that this peptide participates in the mononuclear cell recruitment in experimental nephritis through NF- $\kappa \mathrm{B}$ activation and MCP-1 upregulation, expanding data on ANG II as a proinflammatory mediator [18]

The Renin-Angiotensin-Aldosterone System (RAAS) plays a vital role in regulating the physiological processes of the cardiovascular system. Not only does it function as an endocrine system, but it also serves local paracrine and autocrine functions in tissues and organs. The primary effector molecule of this system, angiotenisn II (ANG II), has emerged as a critical hormone that affects the function of virtually all organs, including heart, kidney, vasculature, and brain, and by both beneficial and pathologic effects. Acute stimulation with ANG II regulates salt/water homeostasis and vasoconstriction, modulating blood pressure, while chronic stimulation promotes hyperplasia and hypertrophy of VSMCs [19].

Given its diverse range of functions and its potency in affecting cardiovascular physiology, it becomes imperative to understand the characteristics of ANG II receptors. Blockade of RAAS has been shown to be beneficial in patients with hypertension, acute myocardial infarction, chronic systolic heart failure, stroke and diabetic renal disease [20]

Aim of the work:

The aim of this study is to:

1- Test and compare the possible protective effects of ACEIs and thiamine in the course of diabetes and its complications in type II diabetic rats.

2- Test the role of inflammatory pathway (cascade) in the promotion \& progression of complications in type II diabetic rats.

\section{Material and Methods}

This study was conducted in El-Kasr El-Eini Physiology Department's Laboratory. 2016.

It lasted 3 months from February 2016 till May

\section{Experimental animals:}

A total of 55 male albino rats were used in this study weighing 150-200 grams.

The animals were housed in wire mesh cages at room temperature, with normal light dark cycle. They were fed the commercial rat chew diet and had free access to water.

These rats were divided into the following groups:

- Group 1: Control group ( $\mathrm{n}=10)$ : Consists of 10 normal rats not subjected to any drug.

- Group 2: Type 2 diabetic rats $(\mathrm{n}=10)$ : They were sacrificed after type II diabetes was confirmed.

- Group 3: Diabetic nephropathy DN rats $(\mathrm{n}=10)$ : Microalbuminuria was established in type II diabetic rats.

- Group 4: Lisinopril protected Diabetic nephropathy DN rats $(\mathrm{n}=10)$ : Diabetic nephropathy rats were treated with oral lisinopril $10 \mathrm{mg} / \mathrm{kg} /$ day for 1 month [21].

- Group 5: Thiamine protected Diabetic nephropathy DN rats $(n=10)$ : Diabetic nephropathy rats were treated with high dose oral thiamine mononitrate $70 \mathrm{mg} / \mathrm{kg} /$ day for 1 month [22]

\section{Induction of type 2 diabetes:}

Beginning on day 0 , rats were fed either normal rodent chow (Group 1) or high fat diet (other groups). On day 14, rats on high fat diet were injected with a single low dose of streptozotocin 
$(\mathrm{HFD}+\mathrm{STZ})(\mathrm{STZ}, 30 \mathrm{mg} / \mathrm{kg}$ i.p., in $0.01 \mathrm{M}$ citrate buffer $\mathrm{pH} 4.3$ ) to induce type 2 diabetes [23]. Consumption of high fat diet leads to insulin resistance and is considered to be a major predisposing factor for type 2 diabetes [24]. Subsequent to STZ treatment, rats had free access to food and water and were continued on their respective diets for the duration of the study.

Characterization of type 2 diabetes and diabetic nephropathy models:

On day 20, in the HFD + STZ groups, type 2 diabetes was confirmed by measuring fasting plasma glucose and insulin levels. Blood sampled from the retro-orbital plexus under diethyl ether anesthesia was used to measure plasma glucose and insulin concentrations. Rats that had high blood glucose level were considered as diabetic, and were used for further study. 10 rats were sacrified and were considered as group 2.

Onset of DN in the remaining rats began subtly after one month of diabetes [25]. It was confirmed by the presence of microalbuminuria. 10 rats were considered DN rats and were categorized as Group 3. Group 4 included 10 rats that were treated with oral lisinopril $10 \mathrm{mg} / \mathrm{kg} /$ day for 1 month [21]. Group 5 included 10 rats that were treated with with high dose oral thiamine mononitrate $70 \mathrm{mg} / \mathrm{kg} / \mathrm{day}$ for 1 month [22].

Blood samples from Groups 1, 3, 4 and 5 were taken at the end of the study protocol.

\section{Methods:}

I- Measurement of arterial blood pressure: Blood pressure was measured in conscious rats immediately before obtainingthe blood samples. The rats had been trained to the apparatus several times beforemeasurement. Blood pressure in the tail region was measured using an electronicelectrosphygmomanometer after the rat was prewarmed for $15 \mathrm{~min}$ for increasing theambient temperature to $37^{\circ} \mathrm{C}$ and maintaining an adequate circulation in the rat's tail to measure the blood pressure reliably.

The Harvard Rat Tail Blood Pressure Monitor system is an electronic versionof the traditional sphygmomanometer cuff method, used to determine human bloodpressure indirectly.

\section{II- Measurment of fasting blood glucose according to (www. amsalliance.com):}

Intended use:

AMS glucose kit utilizes the enzymatic colorimetric method for the quantitative determination of glucose in serum, plasma and urine using the AMS SAT 450 Chemistry System.

III- Measurement of fasting blood insulin (according to De La Rica and Stevens, [26]: Insulin concentrations were measured in previously frozen and thawed serumsamples by enzyme immunoassay using rat insulin ELISA kits.

IV- Calculation of homeostasis model assessement insulin resistance index (HOMA-IR): Calculated as the product of fasting insulin (microunits $/ \mathrm{ml}$ ) and fasting glucose $(\mathrm{mMol} / \mathrm{L})$ divided by 22.5 . Lower index indicates greater insulin sensitivity [27].

HOMA-IR $=\frac{\begin{array}{l}\text { Fasting insulin }(ц ю / \mathrm{L}) \mathrm{X} \\ \text { Fasting glucose }(\mathrm{mmol} / \mathrm{L})\end{array}}{22.5}$

$\mathrm{V}-N F-\mathrm{K}(3$ gene expression semiquantitation (according to Ninfa et al., 2009):

Reverse Transcriptase-Polymerase Chain Reaction (RT-PCR):

1- Total RNA was extracted from whole blood using RNeasy purification reagent (Cat No. 74134, Qiagen, Valencia, CA, USA).

2- Reverse transcription and PCR was conducted using OneStep RT-PCR Kit (Qiagen, USA, catalog number 210212).

\section{PCR detection of beta-actin:}

The presence of RNA in all tissues was assessed by analysis of the "house-keeping" gene b-actin. b-actin primers (forward 5'-TGTTGTCCCT.

GTATGCCTCT-3', reverse 5' - TAATGTCACGCAC GATTTCC-3') were designed from GenBank (accession no. J00691) and amplified a product of 206bp.

\section{Gel electrophoresis:}

PCR products of (NF- $\mathrm{K}(3$ and beta actin) genes were electrophorized on 2\% agarose gel stained with ethidium bromide and visualized by ultraviolet transilluminator. Semiquantitation of PCR product was conducted using a gel documentation system (BioDocAnalyze System and Software, Biometra, Germany, Göttingen).

VI- Detection of albumin in urine (for confirmation of diabetic nephropathy): BCG Albumin Assay Kit (MAK124 Sigma Aldrich) was used to assess albumin in urine. 


\section{Statistical analysis:}

Data were statistically described in terms of mean \pm Standard Deviation $( \pm$ SD) and compared using 2-sided student $t$-test for independent samples. All statistical calculations were done using computer program IBM SPSS (Statistical Package for the Social Science; IBM Corp, Armonk, NY, USA) release 22 for Microsoft Windows.

The $p$-value, or calculated probability was determined. $p$-values less than 0.05 were considered statistically significant. While $p$-values less than 0.01 were considered highly significant. $p$-values more than 0.05 were considered insignificant.

\section{Results}

I- Descriptive data of the five studied groups:

In control Group 1, the results of fasting blood glucose (mg/dl), fasting insulin ( $\mathrm{g} / \mathrm{l}$ HOMA test, NF- $\kappa \mathrm{B}$ gene expression, systolic blood pressure $(\mathrm{mmHg})$ and diastolic blood pressure $(\mathrm{mmHg})$ were respectively $89.600 \pm 20.239(\mathrm{mg} / \mathrm{dl}), 0.461 \pm$ $0.056(\mathrm{~g} / \mathrm{l}) .720 \pm 0.153,0.571 \pm 0.034,112.300 \pm$ $9.250(\mathrm{mmHg})$ and $76.800 \pm 10.830(\mathrm{mmHg})$ (Table $1)$.

In diabetic rats Group 2, the results of fasting blood glucose (mg/dl), fasting insulin ( $\mathrm{g} / \mathrm{l}) \mathrm{HO}-$ MA test, NF- $\mathrm{KB}$ gene expression, systolic blood pressure $(\mathrm{mmHg})$ and diastolic blood pressure
$(\mathrm{mmHg})$ were respectively $212.700 \pm 7.212(\mathrm{mg} / \mathrm{dl})$, $4.190 \pm 0.870(\mathrm{~g} / 1.179 \pm 0.010,0.970 \pm 0.116$, $136.000 \pm 5.164(\mathrm{mmHg})$ and $92.000 \pm 2.582(\mathrm{mmHg})$ (Table 1).

In diabetic nephropathy Group 3, the results of fasting blood glucose (mg/dl), fasting insulin ( HOMA test, NF- $\kappa B$ gene expression, systolic blood pressure $(\mathrm{mmHg})$ and diastolic blood pressure (mmHg) were respectively $229.600 \pm 9.442(\mathrm{mg} / \mathrm{dl})$, $5.140 \pm 0.677(\mathrm{~g} / 1.220 \pm 0.148,1.090 \pm 0.263$, $149.000 \pm 8.433(\mathrm{mmHg})$ and $95.500 \pm 4.378(\mathrm{mmHg})$ (Table 1).

In lisinopril-treated diabetic nephropathy rats Group 4, the results of fasting blood glucose (mg/ $\mathrm{dl}$ ), fasting insulin ( $\mathrm{d} / \mathrm{LOMA}$ test, NF- $\mathrm{\kappa B}$ gene expression, systolic blood pressure $(\mathrm{mmHg})$ and diastolic blood pressure $(\mathrm{mmHg})$ were respectively $197.800 \pm 10.993(\mathrm{mg} / \mathrm{dl}), 3.680 \pm 0.634$ ( 1.157 $\pm 0.038,0.669 \pm 0.102,113.400 \pm 8.316(\mathrm{mmHg})$ and $82.500 \pm 10.906(\mathrm{mmHg})$ (Table 1).

In thiamine-treated diabetic nephropathy rats Group 4, the results of fasting blood glucose $(\mathrm{mg} / \mathrm{dl})$, fasting insulin ( $\mathrm{g} / \mathrm{l}$ HOMA test, NF$\kappa \mathrm{B}$ gene expression, systolic blood pressure $(\mathrm{mm}$ $\mathrm{Hg}$ ) and diastolic blood pressure $(\mathrm{mmHg})$ were respectively $207.400 \pm 5.719(\mathrm{mg} / \mathrm{dl}), 4.940 \pm 0.566$ ( $185 \pm 0.073,0.992 \pm 0.032,136.000 \pm 11.832$ $(\mathrm{mmHg})$ and $93.500 \pm 3.375(\mathrm{mmHg})$ (Table 1).

Table (1): Mean and SD of the parameters measured in the 5 studied groups.

\begin{tabular}{|c|c|c|c|c|c|c|}
\hline & $\begin{array}{l}\text { Blood Glucose } \\
\mathrm{mg} / \mathrm{dl}\end{array}$ & Blood Insulin & $\begin{array}{l}\text { HOMA- } \\
\text { IR }\end{array}$ & $\begin{array}{l}\text { NF- } \kappa \mathrm{B} \text { gene } \\
\text { expression }\end{array}$ & $\begin{array}{c}\mathrm{SBP} \\
\mathrm{mmHg}\end{array}$ & $\begin{array}{c}\text { DBP } \\
\mathrm{mmHg}\end{array}$ \\
\hline \multicolumn{7}{|c|}{ Group 1 (control): } \\
\hline Mean & 89.600 & .461 & .720 & .571 & 112.300 & 76.800 \\
\hline$\pm \mathrm{SD}$ & 20.239 & .056 & .153 & .034 & 9.250 & 10.830 \\
\hline \multicolumn{7}{|c|}{ Group 2 (diabetes): } \\
\hline Mean & 212.700 & 4.190 & 1.179 & .970 & 136.000 & 92.000 \\
\hline$\pm \mathrm{SD}$ & 7.212 & .870 & .010 & .116 & 5.164 & 2.582 \\
\hline \multicolumn{7}{|c|}{ Group 3 (diabetes nephropathy ' $D N$ '): } \\
\hline Mean & 229.600 & 5.140 & 1.220 & 1.090 & 149.000 & 95.500 \\
\hline$\pm \mathrm{SD}$ & 9.442 & 677 & .148 & .263 & 8.433 & 4.378 \\
\hline \multicolumn{7}{|c|}{ Group 4 (DN treated with ACEI): } \\
\hline Mean & 197.800 & 3.680 & 1.157 & .669 & 113.400 & 82.500 \\
\hline$\pm \mathrm{SD}$ & 10.993 & .634 & 0.038 & .102 & 8.316 & 10.906 \\
\hline \multicolumn{7}{|c|}{ Group 5 (DN treated with thiamine): } \\
\hline Mean & 207.400 & 4.940 & 1.185 & .992 & 136.000 & 93.500 \\
\hline$\pm \mathrm{SD}$ & 5.719 & .566 & .073 & .032 & 11.832 & 3.375 \\
\hline
\end{tabular}


II- Comparative data of the five studied groups:

Table (2): Effect of induction of type II diabetes on all studied parameters.

\begin{tabular}{lccccc}
\hline & \multicolumn{2}{c}{ Group 1 } & \multicolumn{2}{c}{ Group 2 } & \begin{tabular}{c}
$p$ - \\
\cline { 2 - 5 }
\end{tabular} \\
\cline { 2 - 5 } & Mean & $\pm \mathrm{SD}$ & Mean $\pm \mathrm{SD}$ & value \\
\hline Blood glucose $(\mathrm{mg} / \mathrm{dl})$ & 89.6 & 20.239 & 212.7 & 7.212 & $0.000^{*}$ \\
Blood insulin $(\propto \mathrm{g} / \mathrm{l})$ & 0.461 & 0.056 & 4.19 & 0.87 & $0.000^{*}$ \\
HOMA-IR & 0.72 & 0.153 & 1.179 & 0.01 & $0.000^{*}$ \\
NF-KB gene expression & 0.571 & 0.034 & 0.97 & 0.116 & $0.000^{*}$ \\
SBP (mmHg) & 112.3 & 9.25 & 136 & 5.164 & $0.000^{*}$ \\
DBP (mmHg) & 76.8 & 10.83 & 92 & 2.582 & $0.000^{*}$ \\
\hline *: $p$-values significant change comparing Group 2 to Group 1.
\end{tabular}

Table (2) shows that there is a highly statistically significant difference between Group 1 and Group 2 as regard fasting blood glucose, fasting blood insulin, HOMA-IR, NF-кB gene expression, SBP and DBP $(p<0.01)$. Group 2 had a higher fasting blood gluocse, fasting blood insulin, HOMA-IR, $\mathrm{NF}-\kappa \mathrm{B}$ gene expression, SBP and DBP.

Table (3) shows that there is a highly statistically significant difference between Group 1 and Group 3 as regard fasting blood glucose, fasting blood insulin, HOMA-IR, NF-кB gene expression, SBP and DBP $(p<0.01)$. Group 3 had a higher blood urea, urinaryalbumin excretion, blood albumin creatinine ratio, fasting blood gluocse, fasting blood insulin, HOMA-IR, NF-кB gene expression, SBP and DBP than Group 1.

Table (3): Effect of ephropathy (DN) on all studied parameters.

\begin{tabular}{|c|c|c|c|c|c|c|c|}
\hline & \multicolumn{2}{|c|}{ Group 1} & \multicolumn{2}{|c|}{ Group 2} & \multicolumn{2}{|c|}{ Group 3} & \multirow{2}{*}{$\begin{array}{c}p- \\
\text { value }\end{array}$} \\
\hline & Mean & $\pm \mathrm{SD}$ & Mean & $\pm \mathrm{SD}$ & Mean & $\pm \mathrm{SD}$ & \\
\hline Blood glucose (mg/dl) & 89.6 & 20.239 & 212.7 & 7.212 & 229.6 & 9.442 & $0.000 *, 0.000 \bullet$ \\
\hline Blood insulin $(\propto \mathrm{g} / \mathrm{l})$ & 0.461 & 0.056 & 4.19 & 0.87 & 5.14 & 0.677 & $0.000 *, 0.014 \bullet$ \\
\hline HOMA-IR & 0.72 & 0.153 & 1.179 & 0.01 & 1.22 & 0.148 & $0.000 *, 0.394$ \\
\hline NF-кB gene expression & 0.571 & 0.034 & 0.97 & 0.116 & 1.09 & 0.263 & $0.000 *, 0.203$ \\
\hline $\mathrm{SBP}(\mathrm{mmHg})$ & 112.3 & 9.25 & 136 & 5.164 & 149 & 8.433 & $0.000 *, 0.001 \bullet$ \\
\hline $\mathrm{DBP}(\mathrm{mmHg})$ & 76.8 & 10.83 & 92 & 2.582 & 95.5 & 4.378 & $0.000 *, 0.043 \bullet$ \\
\hline
\end{tabular}

The table also shows that there is a highly statistically significant difference between Group 2 and Group 3 as regard, fasting blood glucose and $\operatorname{SBP}(p<0.01)$. While there is a statistically significant difference between Group 2 and Group 3 as regard fasting blood insulin and DBP $(p<0.05)$. Group 3 had a higherfasting blood glucose, fasting blood insulin, SBP and DBP, than Group 2. Group 3 had a statistically insignificant higher HOMAIR and NF- $\mathrm{KB}$ gene expression than Group 2.

Table (4): Effect of lisinopril treatment on DN rats for 1 month on all studied parameters.

\begin{tabular}{|c|c|c|c|c|c|c|c|c|c|}
\hline & \multicolumn{2}{|c|}{ Group 1} & \multicolumn{2}{|c|}{ Group 2} & \multicolumn{2}{|c|}{ Group 3} & \multicolumn{2}{|c|}{ Group 4} & \multirow{2}{*}{$\begin{array}{c}p- \\
\text { value }\end{array}$} \\
\hline & Mean & $\pm \mathrm{SD}$ & Mean & $\pm \mathrm{SD}$ & Mean & $\pm \mathrm{SD}$ & Mean & $\pm \mathrm{SD}$ & \\
\hline Blood glucose (mg/dl) & 89.6 & 20.239 & 212.7 & 7.212 & 229.6 & 9.442 & 197.8 & 10.993 & $0.000^{*}, 0.002 \bullet, 0.000 æ$ \\
\hline Blood insulin $(\propto \mathrm{g} / \mathrm{l})$ & 0.461 & 0.056 & 4.19 & 0.87 & 5.14 & 0.677 & 3.68 & 0.634 & $0.000^{*}, 0.151,0.000 æ$ \\
\hline HOMA-IR & 0.72 & 0.153 & 1.179 & 0.01 & 1.22 & 0.148 & 1.157 & 0.038 & $0.000 *, 0.094,0.209$ \\
\hline NF-кB gene expression & 0.571 & 0.034 & 0.97 & 0.116 & 1.09 & 0.263 & 0.669 & 0.102 & $0.010^{*}, 0.000 \bullet, 0.000 æ$ \\
\hline $\mathrm{SBP}(\mathrm{mmHg})$ & 112.3 & 9.25 & 136 & 5.164 & 149 & 8.433 & 113.4 & 8.316 & $0.783,0.000 \bullet, 0.000 æ$ \\
\hline $\mathrm{DBP}(\mathrm{mmHg})$ & 76.8 & 10.83 & 92 & 2.582 & 95.5 & 4.378 & 82.5 & 10.906 & $0.256,0.015 \bullet, 0.003 æ$ \\
\hline
\end{tabular}

*: $p$-values significant change comparing Group 4 to Group 1.

$æ: p$-values significant change comparing Group 4 to Group 3.

- : $p$-values significant change comparing Group 4 to Group 2.

Table (4) shows that there is a highly statistically significant difference between Group 1 and Group 4 as regard fasting blood glucose, fasting blood insulin and HOMA-IR $(p<0.01)$. While there is a statistically significant difference between Group 1 and Group 4 as regard NF- $\mathrm{KB}$ gene expression $(p<0.05)$. Group 4 had a higherfasting blood gluocse, fasting blood insulin, HOMA-IR and NF-
кВ gene expression, than Group 1. Group 4 had a statistically insignificant higher blood urea, SBP and DBP than Group 1.

The table also shows that there is a highly statistically significant difference between Group 2 and Group 4 as regard fasting blood glucose, NF- $\mathrm{KB}$ gene expression and SPB $(p<0.01)$. While 
there is a statistically significant difference between Group 2 and Group 4 as regard DBP $(p<0.05)$. Group 4 had a higher fasting blood glucose, NF$\kappa \mathrm{B}$ gene expression, SPB and DBP, than Group 2. Group 4 had a statistically insignificant lowerfasting blood insulin and HOMA-IR than Group 2.

The table also shows that there is a highly statistically significant difference between Group
3 and Group 4 as regard fasting blood glucose, fasting blood insulin, NF- $\mathrm{\kappa B}$ gene expression, SBP and DBP $(p<0.01)$. Group 4 had a higher blood albumin creatinine ratio, and had a lower fasting blood glucose, fasting blood insulin, NF- $\mathrm{\kappa B}$ gene expression, SBP and DBP, than Group 3. Group 4 had a statistically insignificant lower HOMA-IR than Group 3.

Table (5): Effect of thiamine mononitrate treatment on DN rats for 1 month on all studied parameters.

\begin{tabular}{|c|c|c|c|c|c|c|c|c|c|c|c|}
\hline & \multicolumn{2}{|c|}{ Group 1} & \multicolumn{2}{|c|}{ Group 2} & \multicolumn{2}{|c|}{ Group 3} & \multicolumn{2}{|c|}{ Group 4} & \multicolumn{2}{|c|}{ Group 5} & \multirow{2}{*}{$\begin{array}{c}p- \\
\text { value }\end{array}$} \\
\hline & Mean & $\pm \mathrm{SD}$ & Mean & $\pm \mathrm{SD}$ & Mean & $\pm \mathrm{SD}$ & Mean & $\pm \mathrm{SD}$ & Mean & $\pm \mathrm{SD}$ & \\
\hline Blood glucose (mg/dl) & 89.6 & 20.239 & 212.7 & 7.212 & 229.6 & 9.442 & 197.8 & 10.993 & 207.4 & 5.719 & $0.000^{*}, 0.085,0.000 æ, 0.025$ \\
\hline Blood insulin $(\propto \mathrm{g} / \mathrm{l})$ & 0.461 & 0.056 & 4.19 & 0.87 & 5.14 & 0.677 & 3.68 & 0.634 & 4.94 & 0.566 & $0.000^{*}, 0.035 \bullet, 0.483,0.000$ \\
\hline HOMA-IR & 0.72 & 0.153 & 1.179 & 0.01 & 1.22 & 0.148 & 1.157 & 0.038 & 1.185 & 0.073 & $0.000^{*}, 0.800,0.511,0.296$ \\
\hline NF-кB gene expression & 0.571 & 0.034 & 0.97 & 0.116 & 1.09 & 0.263 & 0.669 & 0.102 & 0.992 & 0.032 & $0.000^{*}, 0.570,0.257,0.000$ \\
\hline $\mathrm{SBP}(\mathrm{mmHg})$ & 112.3 & 9.25 & 136 & 5.164 & 149 & 8.433 & 113.4 & 8.316 & 136 & 11.832 & $0.000 *, 1.000,0.011 æ, 0.000$ \\
\hline DBP (mmHg) & 76.8 & 10.83 & 92 & 2.582 & 95.5 & 4.378 & 82.5 & 10.906 & 93.5 & 3.375 & $0.000 *, 0.279,0.268,0.007$ \\
\hline
\end{tabular}

Table (5) shows that there is a highly statistically significant difference between Group 1 and Group 5 as regard fasting blood glucose, fasting blood insulin, HOMA-IR, NF-кB gene expression, SBP and DBP $(p<0.01)$. Group 5 had a higher fastingblood glucose, fasting blood insulin, HOMA-IR, NF-кB gene expression, SBP and DBP, than Group 1.

The table also shows that there is a there is a statistically significant difference between Group 2 and Group 5 as regard fasting blood insulin $(p<0.05)$. Group 5 had a higherfasting blood insulin than Group 2. Group 5 had a statistically insignificant higher HOMA-IR, NF- $\mathrm{\kappa B}$ gene expression and DBP, and insignificant lower fasting blood glucose, than Group 2.

The table also shows that there is a highly statistically significant difference between Group 3 and Group 5 as regard fasting blood glucose $(p<0.01)$. While there is a statistically significant difference between Group 3 and Group 5 as regard SBP $(p<0.05)$. Group 5 had a lowerfasting blood glucose and SBP, than Group 3.

Group 5 had a statistically insignificant lower fasting blood insulin, HOMA-IR, NF- $\mathrm{\kappa B}$ gene expression and DBP than Group 3.

The table also shows that there is a highly statistically significant difference between Group 4 and Group 5 as regard fasting blood insulin, NF- $\kappa \mathrm{B}$ gene expression, SBP and DBP $(p<0.01)$. While there is a statistically significant difference between Group 4 and Group 5 as regard fasting blood glucose $(p<0.05)$. Group 5 had a higherfasting blood glucose, fasting blood insulin, NF- $\mathrm{\kappa B}$ gene expression, SBP and DBP, than Group 4. Group 5 had a statistically insignificant higherHOMA-IR than Group 4.

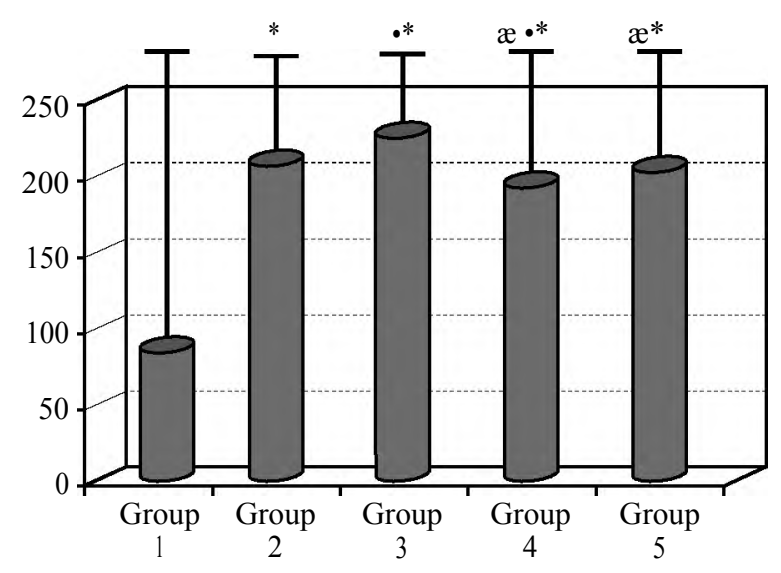

Fig. (1): Mean blood glucose among thestudied groups.

Values are represented as mean $\pm \mathrm{SD}$.

* : Statistically significant change comparing Groups 5, 4, 3 and 2 to Group $1(p<0.05)$.

- : Statistically significant change comparing Groups 5, 4 and 3 to Group $2(p<0.05)$

$æ$ : Statistically significant change comparing Groups 5 and 4 to Group $3(p<0.05)$

$\square$ : Statistically significant change comparing Group 5 to Group 4 $\left(p^{<0.05)}\right.$. 


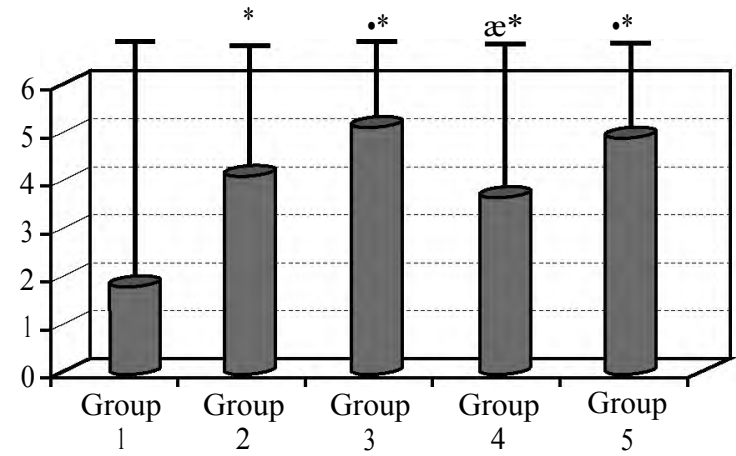

Fig. (2): Mean blood insulin among the studied groups.

Values are represented as mean \pm SD

* : Statistically significant change comparing Groups 5, 4, 3 and 2 to Group $1(p<0.05)$.

- : Statistically significant change comparing Groups 5, 4 and 3 to Group $2(p<0.05)$.

$æ$ : Statistically significant change comparing Groups 5 and 4 to Group $3(p<0.05)$.

$\square$ : Statistically significant change comparing Group 5 to Group 4

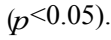

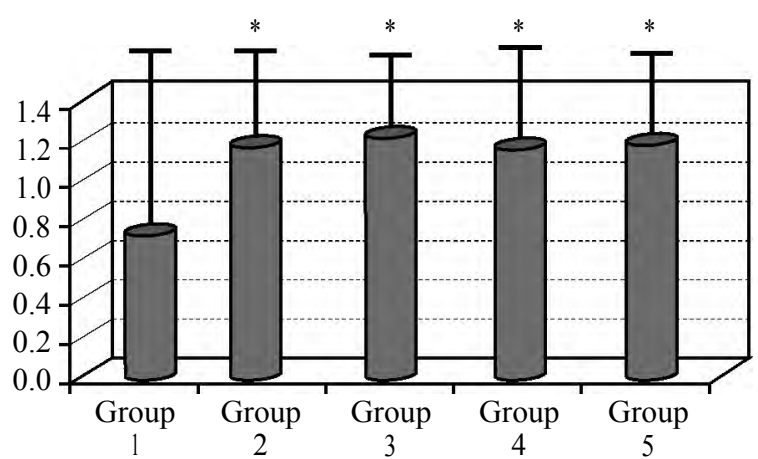

Fig. (3): Mean HOMA-IR among the studied groups.

Values are represented as mean $\pm \mathrm{SD}$.

*: Statistically significant change comparing Groups 5, 4, 3 and 2 to Group $1(p<0.05)$.

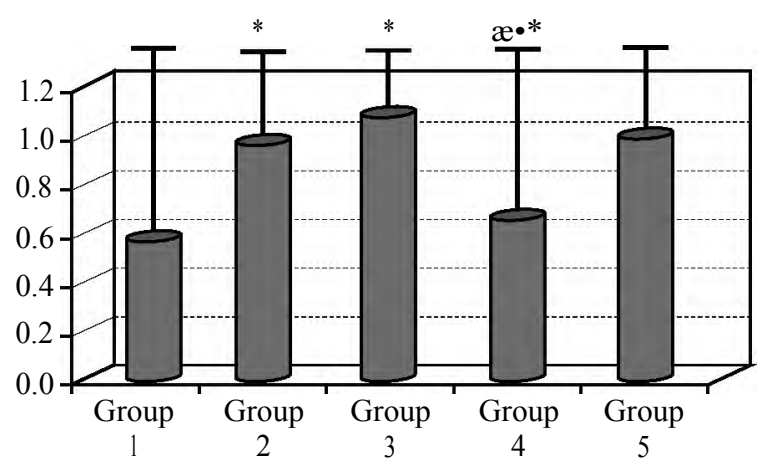

Fig. (4): Mean NF- $\kappa B$ gene expression among the studied groups.

Values are represented as mean \pm SD

* : Statistically significant change comparing Groups 5, 4, 3 and 2 to Group $1(p<0.05)$.

- : Statistically significant change comparing Groups 5, 4 and 3 to Group $2(p<0.05)$

$æ$ : Statistically significant change comparing Groups 5 and 4 to Group $3(p<0.05)$

$\square$ : Statistically significant change comparing Group 5 to Group 4

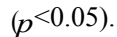

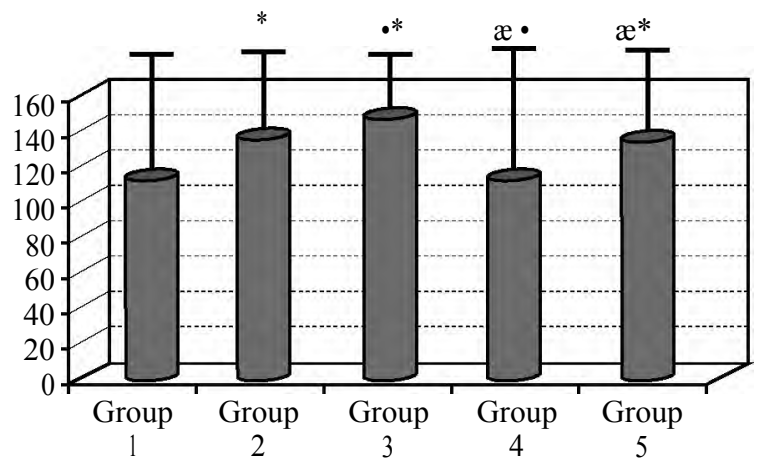

Fig. (5): Mean systolic blood pressure among the studied groups.

Values are represented as mean \pm SD.

* : Statistically significant change comparing Groups 5, 4, 3 and 2 to Group $1(p<0.05)$.

- : Statistically significant change comparing Groups 5, 4 and 3 to Group $2(p<0.05)$.

$æ$ : Statistically significant change comparing Groups 5 and 4 to Group $3(p<0.05)$

$\square$ : Statistically significant change comparing Group 5 to Group 4 $\left(p^{<0.05)}\right.$.

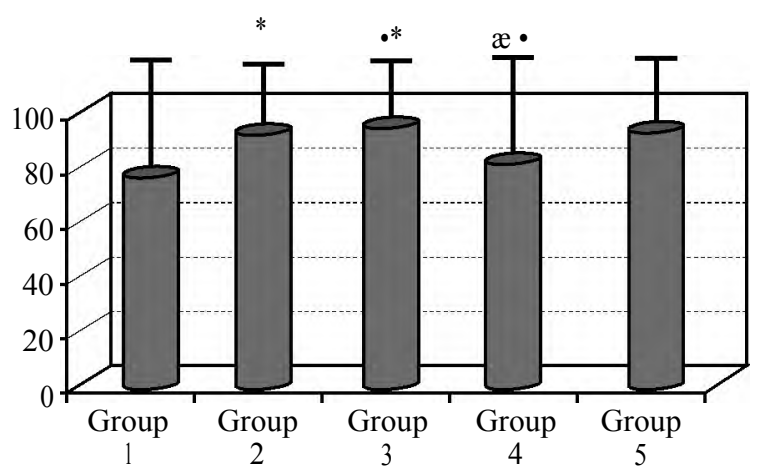

Fig. (6): Mean diastolic blood pressure among the studied groups.

Values are represented as mean \pm SD.

* : Statistically significant change comparing Groups 5, 4, 3 and 2 to Group $1(p<0.05)$.

- : Statistically significant change comparing Groups 5, 4 and 3 to Group $2(p<0.05)$.

$æ$ : Statistically significant change comparing Groups 5 and 4 to Group $3(p<0.05)$.

$\square$ : Statistically significant change comparing Group 5 to Group 4 $\left(p^{<0.05)}\right.$.

\section{Discussion}

The incidence of type $2 \mathrm{DM}$ is increasing worldwide at an explosive rate. The need for research into the pathogenesis, prevention and treatment of diabetes is highlighted by the profound financial, social and personal impact of this devastating disease. DM leads to high nephrogenic morbidity and mortality as a result of functional and morphological damage in diabetic kidneys. The aim of our study is to test and compare the possible therapeutic protective effects of ACE is and thiamine in the course of diabetic complications and nephropathy in type II diabetic rats. And to determine the pos- 
sible role and involvement of the inflammatory pathways in these effects. In this thesis, type II diabetes and insulin resistance were induced by high fat diet for 2 weeks followed by STZ administration. This was evident by the presence of significant increase in the level of fasting blood glucose ( $\mathrm{mg} / \mathrm{dl}$ ), fasting plasma insulin ( $/ \mathrm{L}$ and homeostasis model assessment of insulin resistance (HOMA-IR) in Group 2 (type II diabetic rats). STZ causes hyperglycemia by specifically inducing DNA strand breaks in pancreatic islet-cells and stimulates nuclear poly (ADP-ribose) synthetase, thus depleting intracellular Nicotinamide adenine dinucleotide (NAD+) and Nicotinamide adenine dinucleotide phosphate (NADP+) levels. Reduction of NAD+ and NADP+ inhibits proinsulin synthesis, leading to a diabetic state [28]

Induction of type II diabetes produced a statistically significant increase in SBP and DBP relative to the control group. This result was in agreement with (Zhou et al., 2014) who stated that insulin resistance seems to play a fundamental role in the pathogenesis of hypertension in patients with type 2 diabetes. Moreover, it has been suggested genetic predisposition as a possible mechanism in the pathogenesis [29]

Insulin resistance/hyperinsulinemia is incriminated in the development of hypertension through abnormalities in insulin signalling, associated cardiovascular and metabolic derangements and vascular stiffness. These would include enhanced sympathetic and RAAS activity with subsequent sodium retention and volume expansion, progressive renal disease, cardiac hyperactivity and left ventricular hypertrophy, dyslipidemia, chronic hyperglycemia and increased oxidative stress . In addition, there is endothelial cell dysfunction, including decrease in NO bioavailability, enhanced TXA2 activity, suppressed ANP activity, and activation of epithelial sodium channels. Also there is VSMC dysfucntion including VSMC proliferation and migration, and impaired vascular dilatation. Besides, abnormalities also include maladaptive immune responses where there is increased production of IL-6, IL-8, MCP-1 and TNF- $\alpha$ [30]

Type II diabetic rats showed a statistically significant increase in the level of fasting blood glucose, fasting plasma blood insulin and HOMAIR. Insulin resistance results from impaired insulin signaling cascade at the level of insulin receptor substrate 1 (IRS-1) beside diminished insulin binding and other multiple post-receptor intracellular abnormalities, including impaired glucose transport, glucose phosphorylation, and reduced glucose utilization and oxidation and glycogen synthesis (the impairment in glycogen synthase activation is likely due to a defect in the ability of insulin molecule to phosphorylate IRS-1, causing a reduced association of the p85 subunit of PI 3-kinase with IRS-1 and decreased activation of the enzyme PI3K). Abnormalities of fatty acid metabolism also plays a pivotal role in the pathogenesis of insulin resistance in multiple tissues including skeletal muscles where fatty acid metabolites activate a serine kinase cascade and impair IRS-1 phosphorylation by the insulin receptor, and this leads to defects in insulin signaling and promotes loss of insulin sensitivity in insulin resistant individuals [31].

In addition, as beta-cells in the pancreas work to produce more and more insulin, metabolic stress signals recruit monocytes to clear dying $\beta$-cells. These recruited monocytes differentiate into TNF$\alpha$, IL- 6 and IL- 1 producing macrophages that promote further $\beta$-cell dysfunction and death. TNF$\alpha$ disrupts insulin signaling and sensitivity [32]

Other results in rats strongly suggest that ANG II-induced insulin resistance cannot be attributed to an impairment of the early insulin signaling steps and that oxidative stress, possibly through impaired some insulin signaling steps located downstream from PI 3-kinase activation, is possibly involved in ANG II-induced insulin resistance [33]

Induction of type II diabetes also lead to a significant increase in NF- $\kappa \mathrm{B}$ gene expression. Type II diabetes is associated with low-grade systemic inflammation, which is associated with increased levels of multiple circulating proinflammatory mediators, e.g. TNF- $\alpha$ and gut-derived Lipopolysaccharide (LPS), may play a role in the pathogenesis of insulin resistance, which is the hallmark of type 2 diabetes. The binding of TNF$\alpha$, LPS or other pro-inflammatory ligands to their receptors, activates other intracellular signaling pathways that facilitate the dissociation of nuclear factor NF- $\kappa B$ from an inhibitor of NF- $\kappa B$ (I $\kappa B$ ) proteins. NF- $\kappa B$ subsequently enhancing the transcription of a vast array of genes encoding multiple inflammatory mediators, e.g. TNF- $\alpha$ and IL-6 [34]

Putative stimuli for the NF- $\kappa B$ pathways, such as elevated FFAs, AGEs, ROS and endoplasmatic reticulum stress, are frequently present in diabetic patients. After one month, type II diabetic rats developed DN (Group 3). DN rats showed a statistically significant increase in SBP and DBP relative to both control and diabetic groups. It is now evident that the major causes of hypertension in 
DN include volume expansion owing to increased renal sodium reabsorption and peripheral vasoconstriction owing to dysregulation of factors that regulate peripheral vascular resistance. Activation of the RAAS, upregulation of endothelin1, upregulation of reactive oxygen species molecules, and NO conspire to produce hypertension in this setting [35].

Type II DN rats also showed a statistically significant increase in fasting blood glucose, fasting blood insulin relative to both control and diabetic groups. They showed a significant increase regarding HOMA-IR relative to the control group, but not to the diabetic group. It has been demonstrated that the RAAS regulates skeletal muscle insulin sensitivity through different possible mechanisms. The overactivation of the ACE ANG II/AT1R axis has been associated with the development of insulin resistance, whereas the stimulation of the ACE2/ Ang 1-7/MasR (Mas receptor) axis was found to improve insulin sensitivity [36]

Clinical and pharmacological studies have recently shown that ANG II is a critical promoter of insulin resistance. ANG II exerts its actions on insulin-sensitive tissues such as liver, muscle and adipose tissue where it has inhibitory effects on the Insulin Receptor (IR), IRS proteins and the downstream effectors PI3K, protein kinase B and glucose transporter 4 (GLUT-4). The molecular mechanisms involved have not been completely identified, but the role of serine/threonine phosphorylation of the IR and IRS-1 proteins in desensitization of insulin action has been well established, which occurs by by Janus kinase 2 signalling mechanisms associated with AT1 R stimulation, which attenuates insulin-induced activation of PI3K found to be associated with IRS-1, leading to decreased insulin sensitivity [37].

Angiotensin converting enzyme inhibitor therapy not only inhibits ANG II production, increases the production of the vasodilator factors. ACE inhibitors increase the plasma levels of bradykinin by inhibiting its degradation in rats and in humans. Bradykinin, via its B2 receptors, stimulates different signaling molecules as NO, cGMP, prostaglandin E2, and prostacyclin [37]. Angiotensin converting enzyme inhibitor is also important in improving arterial compliance through cytoprotective effects affecting the vascular endothelium [38]

Diz et al., [39] proposed that the RAAS facilitates the sympathetic nervous system and that ACE inhibition and angiotensin receptor blockade are anti-adrenergic Lisinopril-treated DN rats showed a statistically significant decrease in fasting blood glucose compared to both type II diabetic rats group and DN rats group. While they showed a statistically significant decrease in fasting blood insulin compared the DN group, but not to type II diabetic group. DN rats treated with lisinopril did not show a significant change regarding HOMAIR compared to both diabetic and DN groups. Anyway, values of these parameters in DN rats did not return to that in the control group. Number of studies have also illustrated that drugs that interfere with the renin-angiotensin system may also decrease the levels of advanced glycation endproducts (AGEs) [40]

Findings of previous studies reported that the decrease in glucose levels with ACEI was related to the increase in the insulin pathway and this was supported by the decrease in glucose levels being associated with a significant decrease in insulin levels [41]

Further studies reported that chronic administration of ACE inhibitors to insulin-resistant rodents can increase protein expression of GLUT-4 in skeletal muscle and myocardium. Angiotensin converting enzyme inhibitors increase GLUT-4 concentration/translocation and activate hexokinase, one of the major enzymes of glucose pathway. These changes are probably secondary to activation of the PI3-kinase signaling pathway by enhancing tyrosine phosphorylation of IRS- 1 and improvement of PI3-kinase-IRS-1 complexing Csibi et al., [42] Lisinopril-treated $\mathrm{DN}$ rats also showed a significant decrease in NF- $\mathrm{KB}$ gene expression compared to both type II diabetic rats and DN rats. Howerver, values remained higher than that in the control group. There is a growing evidence that AGE may play an important role in the development of DN. One of the most commonly formed AGE is NCarboxy-Methyl-Lysine (CML). CML-adducts are a major class of AGE that bind to RAGE. Following ligation of the extracellular region, transmembrane downstream signaling by RAGE is now thought to be transduced by the single hydrophobic transmembrane-spanning domain and its short cytosolic tail. This intracellular portion of the molecule is essential for RAGE-triggered signaling and activates NF- $\mathrm{KB}$ coupled signaling. Forbes and coworkers found that there was a selective decrease of CML AGE in response to treatment with ACE inhibitors [43].

It has been shown that ACEI can improve DN by inhibiting the RAAS system to reduce urinary MCP-1 level. The possible underlying mechanism is that ANG II activates NF- $\mathrm{KB}$ pathway to regulate 
transcription and synthesis of MCP-1 and RANTES [44].

This work also aims to study and evaluate the impact of thiamine in the course of DM. Diabetic nephropathy rats treated with thiamine mononitrate for one month (Group 5) showed no change in SBP compared to the diabetic group rats. However, SBP decreased significantly in relation to DN rats, and at the same time was significantly higher in relation to DN rats treated with lisinopril for one month. DBP did not change significantly compared to both the diabetic and DN rats. While it was significantly high compared to DN rats treated with lisinopril for one month. Both SBP and DBP did not reach their control values. A recent study demonstrated that Benfotiamine (a synthetic S-acyl derivative of thiamine) reduces oxidative stress and activates endothelial nitric oxide synthase to enhance the generation and bioavailability of NO and subsequently improves the integrity of the vascular endothelium to prevent sodium arsenite-induced experimental Vascular Endothelial Dysfunction (VED) [45]

The mechanism by which thiamine improves Endothelium-Dependent Vasodilatation (EDV) is not due to a glucose-lowering effect as thiamine had no effect on EDV under normoglycemic conditions. Routine administration of thiamine might improve endothelial function and therefore slow the development and progression of atherosclerosis, especially in patients suffering from impaired glucose tolerance and non-insulin dependent DM who are prone to develop accelerated atherosclerosis [46]

Thiamine administration can prevent the formation of harmful by-products of glucose metabolism, and can reduce the oxidative stress and improve endothelial function. The potential benefit of long-term replacement in those with diabetes is not yet known, but may reduce cardiovascular risk and angiopathic complications [47].

In diabetic nephropathy rats treated with thiamine mononitrate for one month, fasting blood glucose was significantly low compared to DN rats, and was significantly high compared to lisinopril-treated rats for one month. Fasting blood glucose levels did not show a significant change compared to type II diabetic rats. Treatment with thiamine mononitrate showed insignificant decrease in fasting blood insulin compared to DN rats. However, fasting blood insulin was significantly high compared to both type II diabetic rats and lisinopril-treated rats. Both blood glucose and insulin did not return to their control values in thiamine-treated rats. HOMA-IR did not return to its control value and changed insignificantly compared to diabetic rats, DN rats and thiamine-treated rats. Our results regarding fasting blood glucose and fasting blood insulin are compatible with those that announce that thiamine may modulate diabetic complications by controlling glycemic status in diabetic patients [46].

Additionally, deficiency of thiamine was observed to be associated with dysfunction of $\beta$-cells and impaired glucose tolerance [48].

Thiamine deficiency leads to a marked impairment in insulin synthesis and secretion [49].

Besides, published data suggest that thiamine metabolism in diabetes is deficient (Pacal et al., 2014). Thereby insulin deficiency may exacerbate thiamine deficiency and vice versa. Many observational studies and clinical trials have linked several vitamins with the pathological process of diabetes; including thiamine [50].

Administration of thiamine or a derivative can influence carbohydrate metabolism by reducing metabolism through the alternate pathways of metabolism and improving metabolism via the pentose phosphate pathway. This has been demonstrated in diabetic animal models where treatment with thiamine reduced fasting glucose and $\mathrm{HbA} 1 \mathrm{c}$ levels [51].

Combining the use of thiamine with ACEI as a potential effective treatment in diabetic patients should be taken in consideration, and can make us avoid the possible side effects and disadvantages of the prolonged use of ACEI where there are studies that showed that treatment with ACEIs may be associated with so-called "angiotensin escape," characterized by the return of plasma ANG II concentration to pretreatment levels (although the beneficial effects on blood pressure usually persist). It is often assumed that this rebound generation of ANG II occurs through the action of the serine proteases such as cathepsin $\mathrm{G}$ and chymase (chymostatin-sensitive angiotensin II-generating enzyme) [52].

\section{Conclusion:}

From the previously obtained results data in this study showed that there was a significant improvement in both groups exposed to thiamine and ACE inhibitors.

The use of thiamine in type $2 \mathrm{DM}$ significantly lowered the blood glucose level, increased insulin 
sensitivity and lowered the arterial blood pressure may be through its action in preventing the activation of the biochemical pathways (increased flux through the polyol pathway, formation of advanced glycation end products, activation of PKC, and increased flux through the HBP) induced by hyperglycemia in DM. However, its protective effects were less than those offered by the ACE inhibitors. So thiamine maybe used as an adjunctive treatment in type 2 diabetes mellitus. However its effects if used solely as a therapeutic agent to delay the complications is still in doubt and needs further investigations.

\section{Conflict of interest:}

The authors of this study declares that they have no conflict of interests regarding this study.

\section{References}

1- HOWARD B.V., RODRIGUEZ B.L., BENNETT P.H., HARRIS M.I., HAMMAN R., KULLER R.H., et al. Prevention conference VI: Diabetes and cardiovascular disease: Writing Group I: Epidemiology. Circulation, 105 (18): e132-137, 2002.

2- HAIDARA M.A., YASSIN H.Z., RATEB M., AMMAR H. and ZORKANI M.A.: Role of oxidative stress in development of cardiovascular complications in diabetes mellitus. Curr. Vasc. Pharmacol., Jul., 4 (3): 215-27, 2006.

3- VAN DAM P.S., VAN ASBECK B.S., ERKELENS D.W., MARX J.J., GISPEN W.H. and BRAVENBOER B.: The role of oxidative stress in neuropathy and other diabetic complications. Diabetes Metab. Rev., Oct., 11 (3): 18192, 1995.

4- SINGH V.P., BALI A., SINGH N. and JAGGI A.S.: Advanced glycation end products and diabetic complications. Korean J. Physiol. Pharmacol., Feb., 18 (1): 1-14, 2014.

5- HA H. and LEE H.B.: Reactive oxygen species as glucose signaling molecules in mesangial cells cultured under high glucose. Kidney Int. Suppl., 77: S 19-25, 2000.

6- TANG W.H., MARTIN K.A. and HWA J.: Aldose reductase, oxidative stress, and diabetes mellitus. Front Pharmacol., 3: 87, 2012.

7- DRONAVALLI S., DUKA I. and BAKRIS G.L.: The pathogenesis of diabetic nephropathy. Nat. Clin. Pract. Endocrinol. Metab., 4 (8): 444-52, 2008.

8- LIM A.K.H.: Diabetic nephropathy-complications and treatment. Int. J. Nephrol. Renovasc. Dis., 7: 361-81, 2014.

9- MIYATA T., VAN YPERSELE De STRIHOU C., UEDA Y., ICHIMORI K., INAGI R., ONOGI H., ISHIKAWA N., NANGAKU M. and KUROKAWA K.: Angiotensin II receptor antagonists and angiotensin-converting enzyme inhibitors lower in vitro the formation of advanced glycation end products: Biochemical mechanisms. J. Am. Soc. Nephrol., 13 (10): 2478-87, 2002.

10- KOBORI H., NANGAKU M., NAVAR L.G. and NISHIYAMA A.: The intrarenal renin-angiotensin system: From physiology to the pathobiology of hypertension and kidney disease. Pharmacol. Rev., 59 (3): 251-87, 2007.

11- KANWAR Y.S., WADA J., SUN L., XIE P., WALLNER E.I., CHEN S., CHUGH S. and DANESH F.R.: Diabetic nephropathy: Mechanisms of renal disease progression. Exp. Biol. Med. (Maywood), 233 (1): 4-11, 2008.

12- SINGH R., SINGH A.K., ALAVI N. and LEEHEY D.J.: Mechanism of increased angiotensin II levels in glomerular mesangial cells cultured in high glucose. J. Am. Soc. Nephrol., 14 (4): 873-80, 2003.

13- MKRTCHYAN G., ALESHIN V., PARKHOMENKO Y., KAEHNE T., LUIGI Di SALVO M., PARRONI A., CONTESTABILE R., VOVK A., BETTENDORFF L. and BUNIK V.: Molecular mechanisms of the non-coenzyme action of thiamine in brain: Biochemical, structural and pathway analysis. Sci. Rep., 5: 12583, 2015.

14- BELTRAMO E., BERRONE E., TARALLO S. and PORTA M.: Effects of thiamine and benfotiamine on intracellular glucose metabolism and relevance in the prevention of diabetic complications. Acta. Diabetol., 45 (3): 13141, 2008.

15-LUONG K.V. and NGUYEN L.T.: The impact of thiamine treatment in the diabetes mellitus. J. Clin. Med. Res., 4 (3): 153-60, 2012.

16-NAVARRO-GONZÁLEZ J.F., MORA-FERNÁNDEZ C., MUROS De FUENTES M. and GARCÍA-PÉREZ J.: Inflammatory molecules and pathways in the pathogenesis of diabetic nephropathy. Nat. Rev. Nephrol., 7 (6): $327-$ 40, 2011.

17- CNOP M., WELSH N., JONAS J.C., JÖRNS A., LENZEN S. and EIZIRIK D.L.: Mechanisms of pancreatic betacell death in type 1 and type 2 diabetes: Many differences, few similarities. Diabetes, 54 (Suppl 2): S97-107, 2005.

18- RUIZ-ORTEGA M., RUPÉREZ M., ESTEBAN V., RODRÍGUEZ-VITA J., SÁNCHEZ-LÓPEZ E., CARVAJAL G. and EGIDO J.: Angiotensin II: A key factor in the inflammatory and fibrotic response in kidney diseases. Nephrol. Dial. Transplant., 21 (1): 16-20, 2006.

19- MEHTA P.K. and GRIENDLING K.K.: Angiotensin II cell signaling: Physiological and pathological effects in the cardiovascular system. Am. J. Physiol. Cell. Physiol., 292 (1): C82-97, 2007.

20- MA T.K., KAM K.K., YAN B.P. and LAM Y.Y.: Reninangiotensin-aldosterone system blockade for cardiovascular diseases: Current status. Br. J. Pharmacol., 160 (6): 1273-92, 2010.

21- WIENEN W., RICHARD S., CHAMPEROUX P. and AUDEVAL-GERARD C.: Comparative antihypertensive and renoprotective effects of telmisartan and lisinopril after long-term treatment in hypertensive diabetic rats. J. Renin. Angiotensin. Aldosterone. Syst., 2 (1): 31-6, 2001.

22- BABAEI-JADIDI R., KARACHALIAS N., AHMED N., BATTAH S. and THORNALLEY P.J.: Prevention of incipient diabetic nephropathy by high-dose thiamine and benfotiamine. Diabetes, 52 (8): 2110-20, 2003.

23- XIANG X., WANG Z., ZHU Y., BIAN L. and YANG Y.: Dosage of streptozocin in inducing rat model of type 2 diabetes mellitus. Wei Sheng Yan Jiu, 39 (2): 138-42, 2010. 
24- KRAEGEN E.W., JAMES D.E., STORLIEN L.H., BURLEIGH K.M. and CHISHOLM D.J.: In vivo insulin resistance in individual peripheral tissues of the high fat fed rat: Assessment by euglycaemic clamp plus deoxyglucose administration. Diabetologia, 1986 Mar., 29 (3): 192-8, 1986.

25- KIRAN G., NANDINI C.D., RAMESH H.P. and SALIMATH P.V.: Progression of early phase diabetic nephropathy in streptozotocin-induced diabetic rats: Evaluation of various kidney-related parameters. Indian J. Exp. Biol., 50 (2): 133-40, 2012.

26- De La RICA and STEVENS M.M.: Plasmonic ELISA for the ultrasensitive detection of disease biomarkers with the naked eye. Nature Nanotechnology, 7 (12): 821-4, 2012.

27- MATTHEWS D.R., HOSKER J.P., RUDENSKI A.S., NAYLOR B.A., TREACHER D.F. and TURNER R.C.: Homeostasis model assessment: Insulin resistance and beta-cell function from fasting plasma glucose and insulin concentrations in man. Diabetologia, 28 (7): 412-9, 1985.

28- RAMESH B., SARAVANAN R. and PUGALENDI K.V.: Effect of Dietary Substitution of Groundnut Oil on Blood Glucose, Lipid Profile, and Redox Status in Streptozotocindiabetic Rats. Yale J. Biol. Med., 79 (1): 9-17, 2006.

29- QI Q., FORMAN J.P., JENSEN M.K., FLINT A., CURHAN G.C., RIMM E.B., HU F.B. and QI L.: Genetic predisposition to high blood pressure associates with cardiovascular complications among patients with type 2 diabetes: Two independent studies. Diabetes, 61 (11): 3026-32, 2012.

30- JIA G., AROOR A.R., DeMARCO V.G., MARTINEZLEMUS L.A., MEININGER G.A. and SOWERS J.R.: Vascular stiffness in insulin resistance and obesity. Front Physiol., 6: 231, 2015.

31- ABDUL-GHANI M.A. and DeFRONZO R.A.: Pathogenesis of insulin resistance in skeletal muscle. J. Biomed. Biotechnol., 476279, 2010.

32- BAKER R.G., HAYDEN M.S. and GHOSH S.: NF- $\mathrm{kB}$, inflammation, and metabolic disease. Cell Metab, 13 (1): 11-22, 2011.

33- OGIHARA T., ASANO T., ANDO K., CHIBA Y., SAKODA H., ANAI M., SHOJIMA N., ONO H., ONISHI Y., FUJISHIRO M., KATAGIRI H., FUKUSHIMA Y., KIKUCHI M., NOGUCHI N., ABURATANI H., KOMURO I. and FUJITA T.: Angiotensin II-induced insulin resistance is associated with enhanced insulin signaling. Hypertension, 40 (6): 872-9, 2002.

34- ANDREASEN A.S., KELLY M., BERG R.M., MØLLER K. and PEDERSEN B.K.: Type 2 diabetes is associated with altered NF- $\mathrm{KB}$ DNA binding activity, JNK phosphorylation, and AMPK phosphorylation in skeletal muscle after LPS. PLoS One, 6 (9): e23999, 2011.

35- VAN BUREN P.N. and TOTO R.: Hypertension in diabetic nephropathy: Epidemiology, mechanisms, and management. Adv. Chronic Kidney Dis., 18 (1): 28-41, 2011.

36- ECHEVERRÍA-RODRÍGUEZ O., Del VALLE MONDRAGÓN L. and HONG E.: Angiotensin 1-7 insulin sensitivity by increasing skeletal muscle glucose uptake in vivo. Peptides, 51: 26-30, 2014.
37- YACOUB R. and CAMPBELL K.N.: Inhibition of RAS in diabetic nephropathy. Int. J. Nephrol. Renovasc. Dis., 8: 29-40, 2015.

38- NEUTEL J.M.: Effect of the renin--angiotensin system on the vessel wall: Using ACE inhibition to improve endothelial function. J. Hum. Hypertens., 18 (9): 599 606, 2004.

39- DIZ D.I., ARNOLD A.C., NAUTIYAL M., ISA K., SHALTOUT H.A. and TALLANT E.A.: Angiotensinpeptides and centralautonomicregulation. Curr. Opin. Pharmacol., 11 (2): 131-7, 2011.

40- NANGAKU M., MIYATA T., SADA T., MIZUNO M., INAGI R., UEDA Y., ISHIKAWA N., YUZAWA H., KOIKE H., VAN YPERSELE De STRIHOU C. and KUROKAWA K.: Anti-hypertensive agents inhibit in vivo the formation of advanced glycation end products and improve renal damage in a type 2 diabetic nephropathy rat model. J. Am. Soc. Nephrol., 14 (5): 1212-22, 2003.

41- BITKIN E.C., BOYRAZ M., TAŞKıN N., AKÇAY A., ULUCAN K., AKYOL M.B. and AKÇAY T.: Effects of ACE Inhibitors on Insulin Resistance and Lipid Profile in Children with Metabolic Syndrome. J. Clin. Res. Pediatr. Endocrinol., 5 (3): 164-9, 2013.

42- CSIBI A., COMMUNI D., MÜLLER N. and BOTTARI S.P.: Angiotensin II inhibits insulin-stimulated GLUT4 translocation and Akt activation through tyrosine nitrationdependent mechanisms. PLoS One, 5 (4): e10070, 2010.

43- FORBES J.M., THORPE S.R., THALLAS-BONKE V., PETE J., THOMAS M.C., DEEMER E.R., BASSAL S., EL-OSTA A., LONG D.M., PANAGIOTOPOULOS S., JERUMS G., OSICKA T.M. and COOPER M.E.: Modulation of solublereceptor for advancedglycationendproducts by angiotensin-convertingenzyme-1inhibition in diabeticnephropathy. J. Am. Soc. Nephrol., 16 (8): 2363-72, 2005.

44- YI B., HU X., ZHANG H., HUANG J., LIU J., HU J., LI W. and HUANG L.: Nuclear NF- KBp65 in peripheralbloodmononuclearcellscorrelates with urinaryMCP-1, RANTES and the severity of type 2 diabetic nephropathy. PLoS One, 9 (6): e99633, 2014.

45- VERMA S., REDDY K. and BALAKUMAR P.: The defensive effect of benfotiamine in sodium arseniteinduced experimental vascular endothelial dysfunction. Biol. Trace. Elem. Res., 137 (1): 96-109, 2010.

46- ARORA S., LIDOR A., ABULARRAGE C.J., WEISWASSER J.M., NYLEN E., KELLICUT D. and SIDAWY A.N.: Thiamine (vitamin B-1) improves endotheliumdependent Vasodilatation in the presence of hyperglycemia. Annals of Vascular Surgery, 20 (5): 653-8, 2006.

47- PAGE G.L., LAIGHT D. and CUMMINGS M.H.: Thiamine deficiency in diabetes mellitus and the impact of thiamine replacement on glucose metabolism and vascular disease. Int. J. Clin. Pract., 65 (6): 684-90, 2011.

48- THORNALLEY P.J.: The potential role of thiamine (vitamin B1) in diabetic complications. Curr. Diabetes Rev., 1 (3): 287-98, 2005.

49- DEBSKI B., KURYL T., GRALAK M.A., PIERZYNOWSKA J. and DRYWIEN M.: Effect of inulin and oligofructose enrichment of the diet on rats suffering 
thiamine deficiency. J. Anim. Physiol. Anim. Nutr. (Berl), 95 (3): 335-42, 2011

50- KARACHALIAS N., BABAEI-JADIDI R., RABBANI N. and THORNALLEY P.J.: Increased protein damage in renal glomeruli, retina, nerve, plasma and urine and its prevention by thiamine and benfotiamine therapy in a rat model of diabetes. Diabetologia, 53 (7): 1506-16, 2010.
51- THORNALLEY P.J., BABAEI-JADIDI R., KARACHALIAS N. and RABBANI N.: Prevention of decline in glycemic control in streptozocin-induced diabetic rats by thiamine but not by Benfotiamine. Diabet. Med., 27 (Suppl 1): $74,2010$.

52- LORENZ J.N.: Chymase: The other ACE? Am. J. Physiol. Renal. Physiol., 298 (1): F35-36, 2010.

\section{الفرق بين التآثيرات العلاجية للثيامين وعقار مثبطات إنزيم الآنجيوتينسين

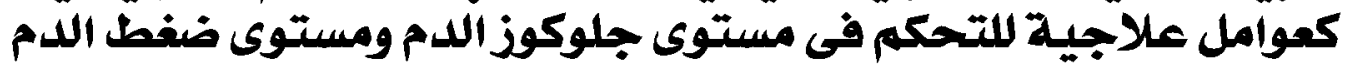

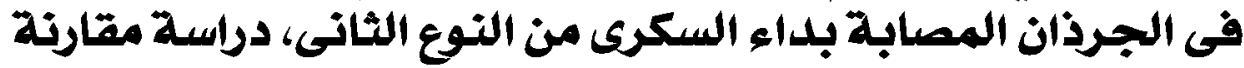

الثيامين هو فيتامين له وظائف فسيولوجية واسعة وآثار علاجية متعددة. آثاره المفيدة فى حالات الآمراض المختلفة هى مجال البحث فى الآى العديد من الآبحاث الديثة. خاصة في لئائل الآمراض المزمنة.

الهدف:إختبار ومقارنة التآثيرات العلاجية المحتملة للعقار المثبط للإنزيم المحل للآنجيوتتسين والثيامين فى الفئران المصابة بداء السكرى من النوع الثانى.

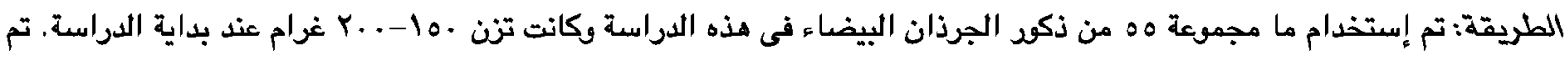

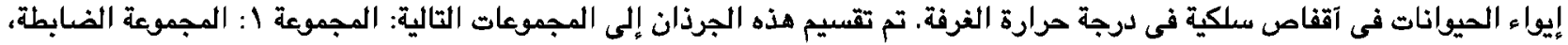

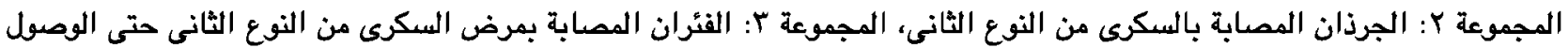

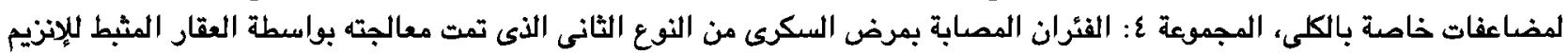

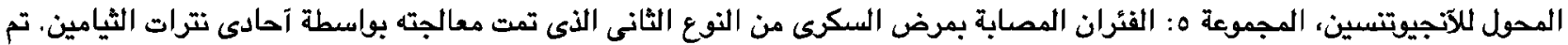

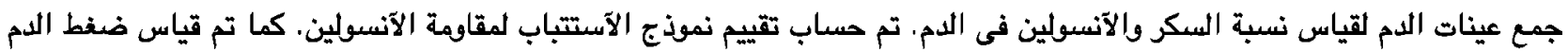

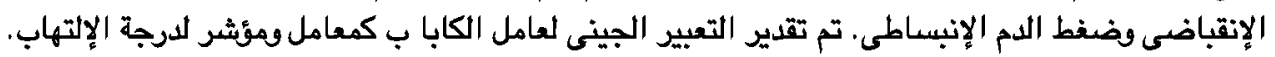

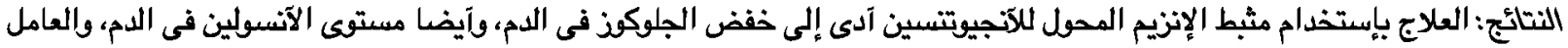

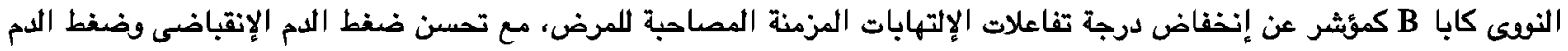

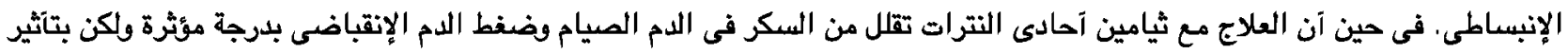

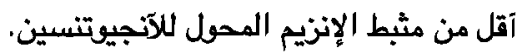

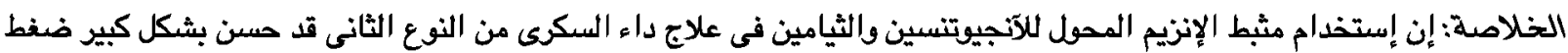

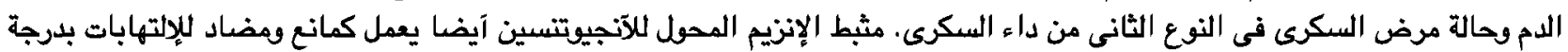

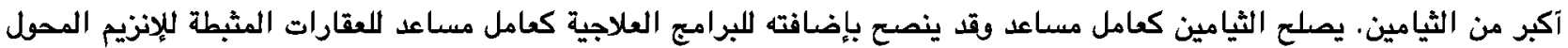

